\title{
Severe Childhood Atopic Dermatitis : Epidemiological and Clinical Features, and Associated Factors in Brazzaville
}

\section{(Congo)}

\author{
Bayonne Kombo ES ${ }^{1,2 *}$ and Gathse $\mathbf{A}^{1}$ \\ ${ }^{1}$ Faculty of Health Sciences, Marien Ngouabi University, Congo \\ ${ }^{2}$ Dermatology and Infectious diseases Department, Talangaï Reference Hospital, \\ Congo
}

*Corresponding author: Bayonne Kombo Edith Sophie, Faculty of Health Sciences/Marien Ngouabi University, PO Box 13423, Brazzaville, Congo, Tel: (242)05578 55 65; Email: sophiekbb@outlook.com

\section{Research article \\ Volume 4 Issue 4}

Received Date: October 14, 2019

Published Date: November 15, 2019

DOI: $10.23880 /$ cdoaj-16000193

\section{Abstract}

Introduction: Atopic dermatitis (AD) is an pruritic inflammatory skin disease, responsible in its severe forms, of psychological disorders and familial stress. The objectives of study were to describe epidemiological and clinical aspects and to determine the factors associated with the severity of atopic dermatitis.

Patients and methods: Descriptive and analytic cross-sectional study, conducted from January 2016 to December 2018 in Brazzaville (Congo) in two health facilities. Children aged between 1 month and 15 years, received for an atopic dermatitis were included. The variables studied were demographic data, clinical data (history of atopy, age at the onset of symptoms, degree of severity appreciated by the SCORAD index, complications) and serum total-IgE level. The processing of data used Epi Info software and the Khi-2 test with Fisher correction or Yates correction as appropriate. The p-value was significant under than 0.05 .

Results: Of the 75 cases of $\mathrm{AD}$ included, 25 were severe, representing a frequency of $33.3 \%$. There were 17 girls (68.0\%) and 8 boys $(32.0 \%)$, mean age 4.6 years $(\mathrm{SD}=3.54)$. All the children came from an urban area. The average duration of disease progression was 39.76 months (SD $=20.7)$. A family history of atopy was noted in 17 cases $(68.0 \%)$. Atopic comorbidity was found in 14 children (56.0\%). The lesions were located on flexure folds in 52\% of case, on face and diffuse in $24 \%$ of cases respectively. Secondary infection was found in $76.0 \%$ of cases $(n=19)$. Total-IgE serum level was elevated in 18 out of 21 children tested (85.7\%). Infectious complications $(\mathrm{p}<0.001)$ and high serum total-IgE level (p $<0.001$ ) were associated with severe AD. 
Conclusion: This study reveals the high frequency of severe form of atopic dermatitis in childhood. It identifies secondary infection and elevated total-IgE serum as factors associated with the severity of the disease. This suggests preventive actions against infection in children with AD.

Keywords: Atopic Dermatitis; Eczema; Severity; Childhood

Abbreviations: AD: Atopic Dermatitis; S. aureus: Staphylococcus Aureus.

\section{Introduction}

Atopic dermatitis (or atopic eczema) is the commonest inflammatory skin disease that is characterised by intense pruritis and recurrent eczematous lesions [1,2]. The overall prevalence of atopic dermatitis (AD) in children ranges from $10 \%$ to $20 \%$ across studies with a wide geographic variety $[3,4]$. Prevalence and incidence of $A D$ varies from country to country and geographically within a country [5]. The disease manifests during the first year of life, but it can start at any age. The diagnosis relies exclusively on clinical features. No specific laboratory or histological findings have been reported for its diagnosis [1].

The impact of $\mathrm{AD}$ on quality of life is similar to that caused by other chronic diseases such as asthma and diabetes [6]. In its moderate and severe forms, AD causes psychological disorders, anxiety, depression, low selfesteem, sleep disorders with repercussions on school performance and familial stress [2,7].

Few data is available concerning epidemiology and the factors involved in severe AD. This gap remains a field of research [8]. In order to improve the quality of life of children with $\mathrm{AD}$, the objectives of our study were to describe epidemiological and clinical aspects and to determine the factors associated with the severity of AD.

\section{Patients and Methods}

This was a bicentric, descriptive and analytic crosssectional study conducted from January 2016 to December 2018 in Brazzaville (Congo) in two health facilities: Talangaï Reference Hospital in Dermatology and infectious diseases Department and Cogemo private Hospital.

The medical records of children aged between 1 month and 15 years, received for an atopic dermatitis, were collected. Incomplete medical records have been excluded. The diagnosis of atopic dermatitis was based on the criteria of the United Kingdom Working Party [9].

The data was collected on a standardized form. The variables studied were demographic data (age, sex, environment of residence), clinical data (atopic history and comorbidity, age at the onset of symptoms, degree of severity, existence and type of complications) and biological data (serum total-IgE level). The degree of severity was appreciated by the SCORAD index [10]. The $\mathrm{AD}$ was classified as mild for a score of less than 15 , as moderate for a score between $15-40$ and as severe for a score above 40 .

The data was processed using Epi Info ${ }^{\circledR}$ software. Qualitative variables were expressed in numbers and percentages. Quantitative variables were expressed as mean and standard deviation (SD). The khi-two test with Fisher correction and Yates correction for small numbers was used for statistical analysis. The $p$-value was significant when it was less than 0.05 .

\section{Results}

\section{Characteristics of the Study Population}

Seventy-five children were included in the study, whose 34 (45.33\%) from a public hospital and 41 (54.67\%) a private hospital. They were 49 girls $(65.33 \%)$ and 26 boys (34.67\%), mean age 4.3 years ( 9 months- 12 years).

\section{Epidemiological and Clinical Features of Severe Atopic Dermatitis}

Of the $75 \mathrm{AD}$ cases included, 25 were severe cases. The frequency of severe AD was $33.3 \%$. There were 17 girls $(68.0 \%)$ and 8 boys $(32.0 \%)$, sex ratio 0.47 . Mean age was 4.6 years $(\mathrm{SD}=3.54)$. Thirteen children $(52.0 \%)$ were seen in a public hospital and $12(48.0 \%)$ in a private hospital. All the children came from an urban area. The average duration of disease progression was 39.76 months ( $S D=20.7)$. The disease started before the age of 
2 years in 22 cases (88.0\%), and between 2 and 5 years in 3 cases $(12.0 \%)$. A family history of atopy was noted in 17 cases (68.0\%). Atopic comorbidity was found in 14 children $(56.0 \%)$. Asthma, allergic conjunctivitis and allergic rhinitis were found in 7 (28.0\%), 5 (20.0\%) and 7 $(28.0 \%)$ cases, respectively.

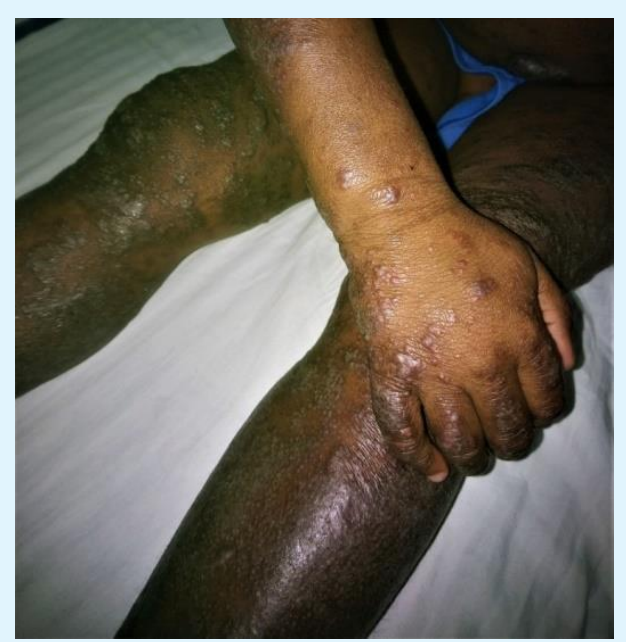

Figure 1: Severe lichenoid atopic dermatitis in a 4 years-old child.
Figure 1 illustrates a severe lichenoid form of $\mathrm{AD}$. Table 1 shows the distribution of severe eczema lesions according to their dominant location.

\begin{tabular}{|c|c|c|}
\hline Location & Number & Percentage (\%) \\
\hline Face & 6 & 24 \\
\hline Flexure fold & 13 & 52 \\
\hline Diffus & 6 & 24 \\
\hline Total & 25 & 100 \\
\hline
\end{tabular}

Table 1: Distribution of severe eczema lesions by dominant location in 25 children with atopic dermatitis.

The complications, found in 19 children (76.0\%), consisted mainly of bacterial secondary infection. Staphylococcus aureus was identified in 12 bacteriological samples taken from the lesions. The total-IgE serum assay was performed in 21 out of 25 children and high total-IgE level was noted in 18 cases (85.7\%).

\section{Factors Associated with Severe Atopic Dermatitis}

The factors associated with the severity of $\mathrm{AD}$ in children, shown in Table 2, were the existence of an infectious complication $(\mathrm{p}<0.001)$ and high serum totalIgE level $(\mathrm{p}<0.001)$.

\begin{tabular}{|c|c|c|c|}
\hline \multirow{2}{*}{ Variable } & \multicolumn{2}{|c|}{ Severe atopic dermatitis } & \multirow{2}{*}{$\boldsymbol{p}$-value } \\
\cline { 2 - 3 } & Yes & No & \\
\hline Familiar history of AD & 17 & 29 & 0.280 \\
\hline Atopic comorbidity & 14 & 21 & 0.184 \\
\hline Oral antibiotic use before consultation & 10 & 14 & 0.214 \\
\hline Local antibiotic use before consultation & 11 & 15 & 0.172 \\
\hline Local antiseptic use before consultation & 11 & 17 & 0.178 \\
\hline Local steroid use before consultation & 11 & 19 & 0.399 \\
\hline Existence of an secondary infection & 19 & 6 & $<\mathbf{0 . 0 0 1}$ \\
\hline High serum total-IgE level & 18 & 7 & $<\mathbf{0 . 0 0 1}$ \\
\hline
\end{tabular}

Table 2: Association of factors with atopic dermatitis.

\section{Discussion}

In order to describe the epidemiological and associated characteristics of severe $\mathrm{AD}$, our selection of the study population was focused on children because childhood is the period of onset [11].

The small sample size was one of the limitations of this study. The severity of AD was assessed based on clinical criteria using the SCORAD index, which has been shown to be effective [12]. Indeed, there is currently no biomarker for routine assessment of the severity of AD [2]. However, in clinical studies, the measurement of the serum marker CCL 17 showed a good correlation with the severity of the clinically appreciated disease [2]. The weakness of our medical platform did not make it possible to use this biomarker.

In our study, the frequency of severe $\mathrm{AD}(33.3 \%)$ was higher than that reported by other authors. In Ivory Coast, it accounts for $2.9 \%$ of cases of AD of childhood [13]. In Tunisia, the severe AD of childhood corresponds to a 


\section{Clinical Dermatology Open Access Journal}

hospital frequency of $0.085 \%$ [14]. Studies in the USA and United Kingdom have shown prevalence of severe AD 7\% and $6 \%$ respectively [15].

Secondary infection complicated $\mathrm{AD}$ in $76 \%$ of our children. These were essentially bacterial. Bacterial infection with Staphylococcus aureus (S. aureus) is commonly described during AD [16,17]. It can cause bacteremia, endocarditis, septic arthritis, and osteomyelitis [18]. Herpes simplex virus secondary infection (eczema herpeticum) may also occur $[16,17]$. It is the most severe infectious complication. It was not observed in our study.

Our study reveals the association between severe AD and infectious complications mainly secondary bacterial infection. The microbiota is the set of microorganisms, saprophytes and pathogens that colonize human organs. It has an anti-inflammatory function and a defense function against infection by pathogenic germs $[19,20]$. The microbiota is disrupted during AD [20,21]. Disturbance is greater in the sites of predilection of lesions such as antecubital and popliteal fossa [21]. Indeed, the dryness and high $\mathrm{pH}$ of the skin as well as the deficit in antimicrobial peptides favor the selection of $S$. aureus within the microbiota [19]. S. aureus is present on the skin of more than $90 \%$ of AD patients in both healthy and affected skin [21]. Bacterial colonization exposes to the risk of secondary infection, particularly by $S$. aureus, which plays a role in inflammatory attacks $[2,19,21]$. The work of Kong, et al showed a correlation between the low diversity of the cutaneous microbiota and the severity of the $\mathrm{AD}$ measured by SCORAD objective [22]. The association between the severity of $\mathrm{AD}$ and infection is supported by several studies. Huang, et al showed that antibiotic treatments had curative efficacy on $\mathrm{AD}$ flares [23]. Hon, et al, evaluating colonization and infection of lesions during $\mathrm{AD}$, reports that S. aureus colonized $31 \%$ of samples from the most severely affected lesions [24]. His study reveals a high risk of infection for: a SCORAD greater than 40, intense lesions (erythema, lichenification, excoriations) and in case of excess transepidermic water loss. Nomura's analysis further shows that the density of $S$. aureus on both regions correlates with the severity of $\mathrm{AD}$ [25].

Our work also shows the association between elevated total-IgE serum and the severity of the disease. This finding is the same for Holm Denmark in a cohort study that reveals severe AD was associated with increased blood eosinophil count as well as the existence of a high level of serum total-IgE [26]. IgE plays a minor role in the pathogenesis of AD [27]. However, the work of Tolte [28], showing the association between IgE-specific against Staphylococcus aureus and severe AD of childhood, let us suggest a dependence between bacterial infection and IgE. This suggestion remains to be proven by subsequent works. Routine IgE assay may, however, be necessary to identify potentially severe cases early.

\section{Conclusion}

This study reveals the high frequency of severe form of atopic dermatitis in childhood and its infectious complications. It identifies secondary bacterial infection and elevated total-IgE serum as factors associated with the severity of the disease.

\section{References}

1. Weidinger S, Novak N (2016) Atopic dermatitis. Lancet 387(10023): 1109-1122.

2. Huang E, Ong PY (2018) Severe Atopic dermatitis in Children. Curr Allergy Asthma Resp 18(6): 35.

3. Nutten S (2015) Atopic Dermatitis : Global Epidemy and Risk Factor. Ann Nutr Metab 66(1): 8-16.

4. Ezzedine K, Kechichian E (2017) Epidemiology of atopic dermatitis. Ann Derm venereol 144 : VS4-VS7.

5. Odhiambo JA, Williams HC, Clayton TO and al (2009) Global variations in prevalence of eczema symptoms in children from ISAAC Phase Three. J Allergy Clin Immunol 124(6): 1251-1258.

6. Beattie PE, Lewis-Jones MS (2006) A comparative study of impairment of quality of life in children with skin disease and children with other chronic childhood diseases. Br J Dermatol 155(1): 145-151.

7. Yaghmaie P, Koudelka CW, Simpson EL (2013) Mental health comorbidity in patients with atopic dermatitis. J Allergy Clin Immunol 131(2): 428-433.

8. Garg N, Silverberg JI (2015) Epidemiology of childhood atopic dermatitis. Clin Dermatol 33(3): 281-288.

9. Williams HC, Burney PG, Hay RJ, Archer CB, Shipley MJ, et al. (1994) UK working party's diagnostic criteria for atopic dermatitis I. Derivation of a minimum set of discriminators for atopic dermatitis. Br J Dermatol 131(3): 383-389. 
10. Kunz B, Oranje AP, Labrèze L, Stalder JF, Ring J, et al. (1997) Clinical validation and guidelines for the SCORAD index: consensus report of the European Task Force on Atopic Dermatitis. Dermatol 195(1): 10-19.

11. Illi S, von Mutius E, Lau S, Nickel R, Gruber $C$, et al. (2004) The natural course of atopic dermatitis from birth to age 7 years and the association with asthma. J Allergy Clin Immunol 113: 925-931.

12. Chopra R, Silverberg JI (2018) Assessing the severity of atopic dermatitis in trials and practice. Clin Dermatol 36(5): 606-615.

13. Ahogo KC, Kouassi YI, Gbery IP, AZagoh KR, Yeboua $\mathrm{KI}$, et al. (2017) Atopic dermatitis in children: Epidemiologiac and clinicals aspects in Côte d'Ivoire. Our Dermatol Oneline 8(1): 25-27.

14. Mahfoudh A, Zaraa I, Amara T, Zribi H, El Euch D, et al. (2014) Severe childwood atopic dermatitis. La Tunisie medicale 92(4): 249-252.

15. Sun D, Ong PY (2017) Infectious complications in atopic dermatitis. Immunol Allergy Clin N Am 37(1): 75-93.

16. Kim KH (2014) Clinical pearls from atopic dermatitis and its infectious complications. $\mathrm{Br} \mathrm{J}$ Dermatol 170(1): 25-30.

17. Patel D, Jahnke MN (2015) Serious Complications from Staphylococcal aureus in Atopic Dermatitis. Pediatr Dermatol 32(6): 792-796.

18. Hacard F, Nosbaum A, huynh VA, Nicolas JF, Bérard F (2014) Diversity of cutaneous bacteria decreases inflammation. Ann dermatol Venereol 142(1): S13-17.

19. Paller AS, Kong HH, Seed P, Naik S, Scharschmidt TC, et al. (2019) The microbiome in patients with atopic dermatitis. J Allergy Clin Immunol 143(1): 26-35.
20. Lacour JPh (2014) Skin microbiota and topic dermatitis: toward new therapeutic options? Ann Derm venereol 142(1): S18-22.

21. Kong HH, Oh J, Deming C, Conlan S, Grice EA, et al. (2012) Temporal shifts in the skin microbiome associated with disease flares and treatment in children with atopic dermatitis. Genome Res 22(5): 850-859.

22. Huang JT, Abrams M, Tlougan B, rademaker A, Paller AS (2009) Treatment of Staphylococcus aureus colonization in atopic dermatitis decreases severity. Pediatrics 123(5): e808-814.

23. Hon KL, Tsang YC, Pong NH, Ng C, Ip M, et al. (2016) Clinical features and Staphylococcus aureus colonization/infection in childhood atopic dermatitis. J Dermatolog Treat 27(3): 235-240.

24. Nomura T, Kabashima K (2016) Advances in atopic dermatitis in 2015. J allergy Clin Immunol 138(6): 1548-1555.

25. Holm JG, Agner T, Clausen ML, Thomsen SF (2019) Determinant of disease severity among patients with atopic dermatitis: association with components of the atopic march. Arch Dermatol Res 311(3): 173-182.

26. Hennino A, Berard F, Nicolas JF (2005) Atopic dermatitis is not a allergic disease. Press Med 34: 7880 .

27. Tolté JEE, Pardon LM, Fieten KB, de Wit J, de Boer DV, et al. (2018) IgE response against Staphylococcus aureus is associated with severe atopic dermatitis in children. Br J Dermatol 179(1): 118-126. 